\title{
RESCATAR DEL OLVIDO (AZORÍN EN BLANCO Y NEGRO)
}

\author{
José MANUEl VidAl ORTUÑO \\ josemanuelvidal@ymail.com \\ IES Yecla
}

\begin{abstract}
Resumen
Atendiendo a las exigencias de este monográfico, se estudian algunos artículos que José Martínez Ruiz escribió para el semanario gráfico Blanco y Negro entre 1904 y 1910. Son, precisamente, aquellos que, en 1963, José García Mercadal recogió en el volumen titulado En lontananza, entre otros tantos de diversa procedencia. Estas colaboraciones fueron una especie de taller literario para Azorín, puesto que las que no pasaron a un libro sirvieron como probaturas para obras o partes de obras posteriores. Otras veces, en cambio, nuestro autor reelaboró escritos ya existentes, dándoles una nueva dimensión. Por último, en las páginas de Blanco y Negro quedaron olvidados bellos cuentos que luego no encontraron cabida en ningún volumen de la amplia creación azoriniana.
\end{abstract}

Palabras clave: Azorín, Blanco y Negro, En lontananza, cuentos, artículos, semblanzas.

\section{Summary}

Some articles written by José Martínez Ruiz for the Blanco y Negro illustrated weekly between 1904 and 1910 were analysed, according to the requirements of this monograph. They were collected by José García Mercadal, in a volume entitled En lontanan$z a$ [In the distance] (1963), alongside many others from varying backgrounds. These collaborations were a kind of literary workshop for Azorín, given that those not made into a book would serve as trials for works or parts of subsequent works. At other times, our author would re-elaborate existing works, giving them new dimensions. Finally, many beautiful stories have remained forgotten in the pages of Blanco y Negro - works which would not be seen in any volume of Azorín's wide range of works.

Keywords: Azorín, Blanco y Negro, En lontananza, stories, articles, resemblances.

Anales, 26, 2014, pp. 521-535

DOI: 10.14198/ALEUA.2014.26.22 
El escritor José Martínez Ruiz tuvo una dilatada y fructífera relación con el semanario Blanco y Negro. Para los límites que impone este monográfico de los Anales de Literatura Española, disponemos de las colaboraciones de Azorín en dicha revista entre 1904 y 1914, puesto que José García Mercadal recopiló gran parte de estos escritos en el libro En lontananza. Con gran perspicacia -y sobre todo, con un azorinismo fuera de toda duda- este crítico vio que en dicho volumen «está ya con todo su relieve el gran escritor de Los pueblos, de España: Hombres y paisajes y de Castilla» (García Mercadal, 1963: 9). Recogió con paciencia artículos olvidados de aquí y de allá, pero al pasarlos de la prensa al libro los ordenó por temas, creando nuevas uniones y destruyendo otras antiguas.

Más allá de García Mercadal, varios estudiosos se han ocupado de estas colaboraciones azorinianas en Blanco y Negro. A ellas alude José María Valverde en su Azorín (1971), aunque no muy extensamente. Se refiere con cierta displicencia al semanario gráfico (al que califica de «revista del hogar, dirigida principalmente a señoras de alta clase media o de la aristocracia»), concluyendo que semejante marco hace que el mundo azoriniano se quede «en cierta insipidez». Llama la atención, eso sí, sobre la cantidad de títulos donde predominan los diminutivos («La viejecita y sus amigos», «La viuda de los cuchillitos») o que portan el adjetivo pequeño (así, «Los pequeños placeres»). Apunta también que hacia 1905 estas colaboraciones se tornan más poéticas (como «Nuestro amigo el reloj»), que hay varias piezas que se inspiraron en la contemplación de un cuadro y que las mejores páginas -y en esto puede que no le falte razón- pasaron a libros como Castilla o España (Valverde, 1998: 315-316). Del camino desde Blanco y Negro hacia España. Hombres y paisajes se ocupó Miguel Ángel Lozano. En un minucioso y acertado trabajo, establece que los años de esplendor de tal colaboración van desde 1907 a 1910; como Valverde, sostiene asimismo que hay al principio un «amaneramiento del propio mundo azoriniano», aunque, a partir de 1905, las colaboraciones de Azorín se tornan «más personales e interesantes» (Lozano, 1990).

Creemos, no obstante, que estas colaboraciones que quedaron en las páginas de Blanco y Negro tienen un cierto interés porque, entre otras cosas, sirvieron de taller literario para nuestro escritor. De las páginas del semanario no solo salieron libros de una gran calidad, sino que también se dio paso a proyectos que quedaron en germen. Hubo por otra parte páginas inolvidables, preciosos cuentos, que no encontraron cabida en ningún libro posterior. Otras páginas, en cambio, fueron simples probaturas, que alcanzaron la excelencia con posterioridad, al ser utilizadas en otras obras. A veces, incluso, para 
satisfacer el compromiso adquirido, Azorín echó mano de lo ya existente, retocando o refundiendo un texto anterior.

De todo esto, en suma, trata mi trabajo: del devenir de unas páginas, que quizás hubiesen dormido en el silencio de las hemerotecas, si no hubiera sido porque, hace cincuenta años, García Mercadal las copió pacientemente, las trasladó a un volumen y les puso un hermoso título: En lontananza. Con una bella portada del pintor Julián Grau-Santos.

\section{Siluetas de la infancia}

Este título, sin duda alguna, le vendría muy bien a una serie de artículos publicados en 1904, los cuales, por su temática y tono, se hallan muy cercanos a algunas páginas de Las confesiones de un pequeño filósofo (1904) o de Los pueblos (1905), pero que por las razones que fueren no encontraron un hueco en ninguna de estas obras. Así, «La viejecita y sus amigos» (27.2.1904) recoge un hecho que, tal vez, pudo acaecer en Monóvar: la apropiación paulatina del ingente patrimonio de una anciana por parte de unos vecinos suyos; tras la muerte de esta mujer «sus amigos entran en posesión de su fortuna» y la moraleja que se extrae de este relato es la siguiente: «ellos han 'secado' bien a la pobre vieja».

José Martínez Ruiz debió conocer a esta y otras figuras borrosas, anodinas allá en su infancia. Las retrata aquí, en estos cuentos, pero reaparecerán, muchos años después, a lo largo de su extensa obra. Son «El pequeño farmacéutico», «La viuda de los cuchillitos» $\mathrm{y}$ «Las camperas levantinas». El primero de ellos (5.3.1904) retrata a «un pequeño farmacéutico que tocaba el violoncelo en la trasbotica»; Azorín insiste en lo verídico de lo que cuenta («Yo lo veía por una ventanita de un desván...», "yo le oía toser...») y lo considera, en su pequeñez, más importante que «esos personajes tremendos de los que habla la Historia». La figura real que hay detrás de este personaje la evocará Martínez Ruiz en Posdata (1959): es un recuerdo de 1879 y el farmacéutico que fascinaba al aprendiz de escritor - «niño, y niño curioso»-se llamaba Raimundo, tenía unos 80 años, aunque no se nos dice que tocara el violonchelo. Encontramos, pues, una de las características de estas colaboraciones de Azorín en Blanco y Negro: el embellecimiento poético de la realidad.

Algo similar ocurre con «La viuda de los cuchillitos» (19.3.1904), un cuento cuyo asunto reaparecerá años después en Superrealismo, la novela de 1929. Sin duda alguna, José Martínez Ruiz debió escuchar -en su casa, en su pueblo- noticias sobre esta mujer, la Viuda des gañivetets, cuya existencia real ha probado José Payá Bernabé (Payá, 2001). Más depurado el recuerdo en la novela, se nos dice tan solo que esta viuda era «opulenta», que vivía en 
«un caserón» y que en 1870 -esto es, unos tres años antes del nacimiento del escritor- hizo traer de Madrid un médico en un tren especial. El cuento de 1904, sin embargo, sustentado sobre esa vaga referencia, resulta mucho más poético: «Yo recuerdo haber visto una vez tan solo, durante mi infancia, a esta pequeña vieja». Aparece además una niña enferma («una niña rubia, pálida, delgada»), a la que la anciana busca remedio inútilmente entre los médicos de Madrid, de Barcelona, de París; pero, sintiendo próxima la muerte de la niña, la viuda de los cuchillitos se la lleva a su pueblo -aquí, innominado- en un tren especial, porque (leemos) «era terrible morir en una ciudad extraña, lejos de la casa del pueblo, lejos de estos campos verdes y de estas colinas luminosas» -y adviértase, otra vez, la cercanía del narrador con lo narrado ${ }^{1}$.

Del costumbrismo, de las notas tomadas de la realidad más inmediata, parece haber nacido «Las camperas levantinas» (4.4.1904). El artículo nos ofrece primero una descripción de la innombrada Monóvar («Esta pequeña ciudad levantina no es adusta como las viejas ciudades castellanas»); luego está el grato sabor de esos parajes de los alrededores, algunos de los cuales tantas veces habrán de salpicar la obra azoriniana: «la Umbría, la Fontana, la Alquebla, Cavafría, Buitrera, Almorquí, Madara, el Collado, el Chinorlet...». El artículo, de un vivo tipismo, consiste básicamente en la descripción de algunas de las tareas que realizan las mujeres en el campo. Después, el uso de palabras en valenciano ("Estig trastornaeta», " No li perteneix!) viene a unir, todavía más, a estas camperas levantinas con la tierra en que viven².

Sin embargo, «Lolita. Historia de una niña que se hará grande» (8.9.1904) ya no encaja en el apartado artículos, sino que constituye un precioso cuento, el cual, incluso, recoge uno de los temas predilectos de Azorín: el del tiempo y su imparable fluir. El relato tiene, además, una estructura compleja, porque el narrador lo es en primera persona, pero es capaz de adivinar el porvenir. Un narrador intemporal que, con el vaivén de las olas, nos va presentando el futuro de Lolita -a los trece, a los dieciocho, a los treinta, a los setenta años-, de esta niña que, efectivamente, se va haciendo grande ante nuestros ojos asombrados. Cuento, por tanto, con saltos temporales, que anuncia, quizás,

1. Personajes sacudidos por la muerte de un ser querido hay varios en la obra azoriniana. Ángel Cruz Rueda (Mujeres de Azorín, Madrid, Biblioteca Nueva, 1953) recordaba algunos ejemplos de muchachas fallecidas en plena juventud: «¡Menchirón!» en Las confesiones..., «Una elegía» en Los pueblos y «Toscano, o la conformidad» en España.

2. No sé si es este el artículo al que hace referencia José Alfonso Vidal en Azorín (de su vida y de su obra), 1931: «Otra tarde, viendo cómo la casera de la Casa del Olmo echaba de comer a los polluelos y gallinas, Azorín tomó apuntes para un magnífico cuento que publicó en Blanco y Negro». 
esas páginas memorables de «Una ciudad y un balcón» (Castilla, 1912) o incluso futuras obras teatrales como Angelita (1930).

En Las confesiones..., José Martínez Ruiz retrató a una parte importante de su familia paterna, la de Yecla; la materna, la que vivió en Petrel, quedó al margen. Tan solo a un familiar, Miguel Amat y Maestre, lo había convertido nuestro escritor en personaje literario como Pascual Verdú en la novela Antonio Azorín, de 1903 (Pavía, 1998). Ahora, tanto el artículo «Los pequeños placeres» (12.8.1905) como la narración evocativa «El abuelo materno» (30.12.1905) están inspirados en José Maestre Pérez, bisabuelo de José Martínez Ruiz. El primero, como bien ha advertido María Martínez del Portal, recuerda una de las aficiones del bisabuelo de Petrel que heredó el bisnieto: ver regar (Martínez del Portal, 1998). En el segundo texto, hay un contraste entre el abuelo paterno (al que se le rinde en la casa «un culto profundo, fervoroso, inquebrantable») y el olvido de este otro que amaba, ante todo, «el silencio, el agua y los árboles» y que «vivía una cosa que el otro no vivía: la vida»3 . Un cuento basado en este -quizás con mayor elaboración literaria, aunque con menos espontaneidad- es «La familia» (incluido en Lecturas españolas, 1912); un relato muy teatral, de hondo simbolismo (Lozano, 1993), que presenta una velada familiar en la que se habla «de un antepasado querido».

\section{Proyectos y tentativas frustrados}

La fotografía como fuente de inspiración no es nada nuevo en la obra de José Martínez Ruiz. Todo lector atento de la novela La voluntad, de 1902, recuerda cómo Antonio Azorín reflexiona sobre el tiempo y su imparable fluir mirando unas viejas fotografías del siglo XIX. Entre 1904 y 1907, Martínez Ruiz escribe en Blanco y Negro unas cuantas colaboraciones que parten de fotografías (ya reales, ya inventadas) y crea cuentos -o casi cuentos, según se mire- que pudieran haber constituido un libro. «Un retrato histórico» (19.10.1904), acaso el mejor, narra el viaje a Madrid que realizaban las muchachas de provincias, el cual quedaba inmortalizado en un retrato hecho por un fotógrafo de la capital (un viaje que tal vez hiciera la madre del escritor).

3. No todos los críticos que se han acercado a este texto son del mismo parecer. Salvador Pavía (1998: 11-48) y José Payá Bernabé (1998: 101-116) lo relacionan con el casi desconocido abuelo materno, Amancio Ruiz Mira, fallecido tempranamente; sin embargo, María Martínez del Portal -apoyándose en un epistolario inédito- ve más bien la sombra del bisabuelo José Maestre Pérez (1998: 85-89). Asimismo, el abuelo paterno que se nombra es realmente el bisabuelo José Soriano García, que aparece en Las confesiones... en el capítulo «El abuelo Azorín». 
«Don Antonio» (16.6.1906), otro logrado cuento, se basa en un escritor real, Antonio María Segovia; relata un día cualquiera de 1861, cuando este periodista ha de interrumpir la crítica teatral que está redactando para acudir al fotógrafo (quien «ha hecho ya los retratos de multitud de personalidades importantes de la política y de la literatura: en la colección falta la efigie del insigne humorista»); este lo fotografía sentado, mientras don Antonio sostiene en la mano un pañuelo «como las infantitas de Velázquez». Luego, de vuelta de nuevo a casa y a su tarea, continúa con su crítica, que queda inacabada ante los ojos del lector ${ }^{4}$.

Por otro lado, «Una tapada» (2.7.1906) es la ensoñación del narrador sobre una enigmática mujer, cuya fotografía dice haber encontrado «un día de aburrimiento en el fondo de una vieja cómoda, en el rincón de un armario que no se ha abierto hace mucho tiempo» y que tiene «una aureola de misterio, de poesía y de atracción profunda». Finalmente, «Los viejos fotógrafos» (22.6.1907) es un artículo, en el cual se recomienda al lector que huya de «estos fotógrafos novísimos, modernistas» y busque a esos viejos fotógrafos que retrataron a Antonio María Segovia, a Ayala, a Julián Romea o a Pedro A. de Alarcón ${ }^{5}$.

Otro grupo lo forman unos artículos que nacen al calor del viaje a Londres que hizo Alfonso XIII en 1905 y que Azorín cubrió para ABC. Las reminiscencias de aquella estancia en el Reino Unido quedan plasmadas en artículos y cuentos de asunto inglés ${ }^{6}$. Así, en «Añoranzas de Londres. El asombro de Maud» (21.9.1905), nuestro escritor imagina cómo habría de ser la existencia de esta «inglesita fina, espiritual, delicada» trasplantada a España, viviendo en una casa vieja, «siempre metida en una sala en que habrá una cómoda vetusta» y, encima de ella, dentro de un fanal de vidrio, «una Virgen pequeña, vestida de negro, con un corazón de plata en el pecho, lleno de espadas».

4. A don Antonio María Segovia Izquierdo (1808-1874) lo vimos en otra fotografía observada por Antonio Azorín en el capítulo X de la segunda parte de La voluntad, aunque en esta aparece «de pie, fino, atildado, con los guantes en mano al estilo velazqueño». Podría figurar, asimismo, ente esos personajes decimonónicos, como Arrazola, Carlos Rubio, Oudrid, presentes en España. Hombres y paisajes.

5. La fotografía como fuente de inspiración ya aparece en La voluntad, en Los pueblos («Una elegía») e influirá posteriormente en la novela Doña Inés (cap. II «El daguerrotipo»), de 1925 (Lozano, 1990). Seguirá teniendo importancia en lo sucesivo; recordemos el magnífico cuento «El otro y el mismo», Visión de España, 1941. Fuera de Azorín, podríamos citar la novela El retrato oval (1971), del también alicantino Juan Gil-Albert.

6. No todas las «añoranzas de Londres»-según las define García Mercadal- aparecieron en Blanco y Negro; algunas se desviaron hacia el diario $A B C$, como «Un viejecito» (4.7.1906), evocación de un español, Manuel García, con el que coincidió el autor en la Embajada de España con motivo de la recepción ofrecida por el Rey Alfonso XIII. 
Basándose en unas notas de la revista londinense The Spectator, sugiere Azorín, en relación con el título, que los políticos se planteen «El voto de los perros» (15.12.1906), ya que estos, con su buen olfato, elegirán siempre a los mejores políticos. Más importancia tiene, sin embargo, un artículo posterior, «Los canes» (16.11.1907), en donde quedan establecidas las distintas condiciones sociales de estos animales; a saber: los canes burgueses, los canes callejeros, los canes campestres y, por último, los canes que moran en las estaciones del ferrocarril. Sobre la misma plantilla, Azorín escribirá después un relato, en el que la voz de narrador se cede a estos simpáticos perros de naturaleza cervantina; su título, «Coloquio de los canes» ${ }^{7}$, el cual en algún momento -años 1909 y 1916- sirvió de cierro como «Epílogo de los canes» a Las confesiones de un pequeño filósofo. Cabe considerar, por tanto, «El voto de los perros» como probatura de lo que después será un magnífico cuento, que, desaparecido de Las confesiones... en su edición definitiva (la de 1920), no se halla en ningún libro de Azorín.

En este apartado que nos ocupa, están, asimismo, dos cuentos protagonizados por objetos muy vinculados a la más pura cotidianidad. Uno de ellos, «Nuestro amigo el reloj» (23.9.1905), narra las tribulaciones de un personaje, cuya vida se ve alterada por algo en apariencia tan insignificante como una avería en su reloj. El otro, «La compra de un sombrero» (7.10.1905), también se basa en un hecho intrascendente: la sustitución de un viejo sombrero por otro nuevo en un provinciano que, de tarde en tarde, arriba a la capital -un argumento que ya apareció, esbozado, en Los pueblos («Una elegía»)-. Con toda razón, Miguel Ángel Lozano afirmó que eran relatos basados en objetos pequeños y recordó al gran estudioso del cuento Mariano Baquero Goyanes (Lozano, 1990).

\section{Lo que no halló cabida en España. Hombres y paisajes}

Para este libro, España. Hombres y paisajes, Azorín escogió «Don José Nieto» (11.11.1905), un cuento que tácitamente inaugura la serie «Los amigos del Museo», la cual tiene la pintura como fuente de inspiración (Lozano, 1990; Esteve, 1995). Quedaron, pues, entre las páginas de Blanco y Negro otras colaboraciones como «Un sensual» (9.12.1905), sobre un matrimonio retratado por Lorenzo Lotto, y «Un magistrado» (13.1.1906), que toma como pretexto

7. E. Inman Fox (1992) da la referencia del Diario de Barcelona, 11.5.1909. Según Miguel Ángel Lozano, «El coloquio de los canes» apareció también publicado en el monovarense periódico El pueblo el 3.7.1909 (Azorín, Obras escogidas, I, Madrid, Espasa Calpe, 1998, p. 1561). 
el retrato del licenciado don Diego del Corral y Arellano, por Velázquez. Este último desarrolla un argumento desviado con respecto a lo que anuncia el título, ya que en lugar del licenciado Del Corral, Azorín nos habla del desventurado don Rodrigo Calderón, valido del todopoderoso duque de Lerma y hombre influyente en el reinado de Felipe III. Tan sugestivo personaje debió impresionar tanto a Azorín que le dedicará más atención en El Político (1908), en los capítulos que van del XXI al XXIV.

«Un buen señor» (2.12.1905) -también de la serie «Los amigos del Museo»- se basa en una tabla pintada por Pedro Berruguete y de ella Azorín extrae, como en tantas ocasiones, un personaje secundario. Su protagonista es un hombre «sencillo, discreto, apacible», que debe asistir a un auto de fe. Se nos muestra su carácter olvidadizo, su retraso en llegar, su indiferencia ante el dolor de los reos y la crueldad humana. Tanto es así, que ante escenas espeluznantes, «nuestro buen amigo dormita sosegado». El lector ha de sacar una conclusión bien distinta al juzgar tanto a este «buen señor» como los hechos luctuosos que este presencia. Algo que, sin salir de la obra azoriniana, ya vimos en El alma castellana, de 1900 (capítulo VII, «La Inquisición», donde es descrito con todo pormenor otro auto de fe). Y, si viajamos hacia atrás en el tiempo, cabe mencionar un cuento semejante de Pedro Antonio de Alarcón, «El rey se divierte», incluido en sus hoy un tanto olvidadas Historietas nacionales.

De otra serie, «Los oficios», tampoco fueron recopilados para España ni «El morenero» ni «El herrero» (tal vez porque estos no alcanzaron la perfección formal ni el lirismo de «El anacalo», «El apañador»o «El melcochero») ${ }^{8}$. «El morenero» (25.5.1907) nos presenta la costumbrista faena de unos esquiladores; aunque, más que el oficio en sí, llama la atención el diálogo que los personajes mantienen sobre un convecino que acaba de morir (otro caso, pues, de argumento desviado con respecto a lo que el título anuncia). Y «El herrero» (24.11.1906), en su sencillez, está cargado de resonancias, que remiten a la infancia del escritor, cuando Azorín era todavía José Martínez Ruiz, un colegial que estudiaba en los escolapios de Yecla. Muestra una escena que tiene lugar en una fragua, regentada por Pedro y Leandro, con un ayudante al que llaman Pascualico -y el diminutivo pienso que es importante ${ }^{9}-$. Por

8. Otros oficios como «Los libreros de viejo» o «Los herbolarios» sí que encontraron un hueco en Madrid (Guía sentimental), 1918, un libro que salió enteramente de las páginas de Blanco y Negro y al que, según Miguel Ángel Lozano, se le ha prestado poca atención crítica (Lozano, 1990).

9. Según Miguel Ortuño y Carmen Ortín, autores de un Diccionario del habla de Yecla (Murcia, Real Academia Alfonso X el Sabio, 1999), es «el diminutivo en 'ico» un rasgo distintivo en la manera de expresarse de los yeclanos. 
ella pasa un lugareño que le recuerda a Pedro el encargo de una «cerrajica» para el portalón del «corralico» de su casa y que (según dice) «está haciendo mucha falta».

Pienso que esta es una escena que alguna vez pudo presenciar José Martínez Ruiz en Yecla, allá en su niñez o en su mocedad. En Las confesiones..., capítulo «El monstruo y la vieja», el escritor evoca la casa de su tío Antonio, donde «al lado, en la herrería paredaña, suenan los golpes joviales y claros de los machos que caen sobre el yunque». Esa fragua, al igual que tantas otras cosas, no resiste el paso del tiempo, según el mismo escritor deja constancia en el «Epílogo», cuando regresa, años después, a la misma casa en que vivió dicho familiar: «La fragua que había paredaña ya no repiquetea; al pasar ya no he podido ver el ojo vivo del hogar que brillaba en el fondo oscuro». Varias décadas después, volverá a recordarla en Agenda (1959), junto a la evocación cariñosa de su tío Antonio («Un epicúreo sin saberlo»), el cual -nos dice- «vivía junto a una herrería». Una casa y una herrería, que antes (1902) habían quedado literaturizadas en La voluntad; concretamente en el capítulo II de la primera parte, convertida aquella en la vivienda del cura Puche: «en la vecindad los martillos de una fragua tintinean argentinos» (Martínez del Portal, 1997).

En relación con el cuento anterior -qué duda cabe- está «Una vieja ciudad» (27.4.1907). Aunque innominada, la panorámica retratada se corresponde con Yecla. Veamos: el sonido que predomina -como en La voluntad-es el de las campanas; aparece la iglesia Vieja, que es «la antigua parroquia de la ciudad»; está la iglesia Nueva, «que ha destronado al viejo y simpático templo gótico» y que es «herreriana, clásica, fría». Por las naves de este último templo transitan unas muchachas que se llaman «Lolita, Iluminada, Consolación» (el nombre de Iluminada nos vuelve a remitir a La voluntad). Y por la sacristía se pasea fumando el cura D. Pedro Marco, gran cazador, obsesionado con sus perdices, quien recuerda «una cacería soberbia que hizo el año 87 en el pueblo de Marisparza» ${ }^{10}$. Y en la ciudad hay también viejecitos, un antiguo casino, un muñidor que avisa de los entierros, herrerías, carpinteros, labradores. Unas notas, en definitiva, que nos hacen volver nuevamente a $\mathrm{La}$ voluntad, presentando una estampa de Yecla en miniatura, y una escena muy parecida a la del capítulo IV, primera parte de la citada novela. Allí -lo ha de

10. Marco es un apellido yeclano, como otros que aparecen en La voluntad (Martínez del Portal, 1997). El cambio del nombre del clérigo -Pedro por José- puede considerarse recurso cervantino. La mención de Marisparza (realmente paraje, no pueblo) solo en el cuento, no en la novela, establece un diálogo con Camino de perfección, 1902, de Pío Baroja, donde Yécora es Yecla y Marisparza se cita con el mismo nombre. 
recordar el lector-, en la sacristía de Santa Bárbara, un cura pregunta a otro si el macho de D. José Marco es mejor que el suyo, antes que otro personaje traiga consigo la noticia de que Puche ha sido nombrado párroco de la iglesia Nueva. Es un cuento que, esta vez, nos presenta una secuencia ya conocida con algunas variantes, es cierto-, pero desde otra perspectiva (desde la iglesia Nueva), contribuyendo así a ese simultaneísmo tan alabado de los primeros capítulos de la novela de 1902. En cualquier caso, «Una vieja ciudad» pudo servir de falsilla para escribir «Una ciudad castellana», el capítulo de España. Hombres y paisajes (Vidal Ortuño, 2007).

\section{El sentimiento de la naturaleza, del paisaje}

Decía Yuste, en La voluntad (capítulo XIV de la primera parte), que «un escritor será tanto más artista cuanto mejor sepa interpretar la emoción del paisaje». Y José Martínez Ruiz, en estos años que nos ocupan, dedicará máxima atención a este tema, en el que acabó siendo maestro indiscutible.

Son varios los artículos -de 1906 y 1907- en los que el paisaje aparece como tema literario primordial. Uno de los primeros es «Valencia y Murcia» (18.2.1906), en el cual Martínez Ruiz se refiere a los paisajes cambiantes de esta zona de España, para detenerse, finalmente, en «la región montañosa alicantina, la tierra alta, el Alicante clásico, castizo, la parte de Monóvar, del Pinoso, de Petrel, de Villena», donde -continúa diciendo- «todo es más sobrio, más seco, un poco más adusto»; una sobriedad, una sequedad y una adustez que terminarán por recordarle al escritor el paisaje de la Grecia clásica. Esta convicción se irá afianzando -y ampliando, también- cuando nuestro escritor se acerque otra vez a estas tierras levantinas en su novela (o pre-novela) Superrealismo -pensemos en el capítulo XII, «Griego y árabe».

Azorín, que ha recorrido muchas tierras de España, sabe que un paisaje es, ante todo, la naturaleza mirada y admirada con ojos de artista. Y sabe asimismo que entre un paisaje y el ojo que mira, que observa, que se deleita ante lo contemplado, se interponen, a menudo, la historia y la literatura. De ahí, sin duda, la importancia de un artículo como «La ruta del Lazarillo» (9.2.1907). Sostiene Azorín la tesis de que una obra literaria nos hace mirar un paisaje de una determinada forma. Por eso, su obra La ruta de don Quijote es un viaje físico, pero también sentimental y literario, por los lugares cervantinos. Martínez Ruiz propone ahora hacer lo mismo siguiendo los pasos de la novela Lazarillo de Tormes. La sola mención de pueblos y ciudades -Salamanca, Escalona, Torrijos, Maqueda, Toledo- es capaz de emocionar a todo lector culto y sensible, solamente porque por ellos anduvo el simpático protagonista de la novela. Lo que aquí es mero proyecto de un libro se hace teoría en «El 
paisaje de España» (23.2.1907). A imitación del inglés sir Archibald Gelkie, Martínez Ruiz propone que se estudie el paisaje en la historia a través de los textos literarios, es decir, de la mano de Berceo, del Arcipreste, concluyendo, tal vez, con Garcilaso y Fray Luis, «los escritores clásicos que han sentido con más profundidad el campo...». Sugiere, además, que dicho estudio se amplíe con las aportaciones de pintores como Velázquez y Goya.

Después, como en tantas otras veces, nuestro escritor pasa de lo general a lo particular o, si se prefiere, de la teoría a la práctica. Ficcionalmente, un poeta añora una vida retirada en el campo en «La oración del poeta», como nueva versión del horaciano Beatus ille. Este poeta que solo aspira al apartamiento, lejos de la vanidad mundana, dice: «Dame, Señor, una casa tranquila y en el campo». Termina diciendo: «Y así, Señor, deseo pasar el resto de mis días: olvidado de todos, obscurecido, sin que nadie me nombre, sin que nadie me escriba». Por estos motivos -profunda religiosidad, desprecio de la ansiada fama literaria- siempre he considerado este texto como un cuento y no como una manifestación de naturaleza autobiográfica ${ }^{11}$. Es simplemente una de las muchas páginas azorinianas que inciden en uno de los temas más reiterados por el autor: la búsqueda de la felicidad ${ }^{12}$.

Ese deseo de huir del mundanal ruido se hace realidad, digamos, en «La vuelta con Josefina» (26.10.1907). Y es que 1907 fue un año complicado para el escritor Martínez Ruiz. Estuvo enfermo, se retiró a Monóvar, escribió poco en los periódicos y pasó parte de su convalecencia en el Collado de Salinas (Inman Fox, 1992; Francisco J. Martín, 2007). En el cuento que nos ocupa, otro poeta, después de doce o catorce años, vuelve a la finca familiar donde escribió sus libros más inspirados. A la manera de un nuevo Ulises que retorna a Ítaca, lo recibe un perro, Romito, viejo conocido del poeta. Va con él Josefina, su compañera ${ }^{13}$. El escritor que regresa a la casa de campo

11. Lo que no quita para que un estudioso como Santiago Riopérez Milá advirtiese en «La oración del poeta»-«bellísimo poema en prosa»- un reflejo del estado de ánimo de Azorín en 1907, viendo «cómo su alma, aun rodeada por el triunfo y la fama, destilaba gotitas de suave misantropía» (1979: 406)

12. También en «Un tren que pasa», Diario de Barcelona, 8.2.1910; en Palabras al viento (1944). Nos lo hace ver María Martínez del Portal en «Yecla en la obra de J. Martínez Ruiz», Homenaje a Azorín en Yecla, Murcia, CAM, 1988.

13. Por estas fechas -finales de 1907- tenía lugar el noviazgo entre J. Martínez Ruiz y Julia Guinda Urzanqui, que acabará en boda el 30 de abril del año siguiente. El mismo escritor reconoció haber retratado a su esposa en El licenciado Vidriera, visto por Azorín, en la figura de Gabriela (Memorias inmemoriales, cap. XXII). Otros críticos ven la sombra del matrimonio Azorín en los ancianos protagonistas de la novela El enfermo; el más reciente, Francisco Javier Díez de Revenga («Introducción»a El enfermo, Madrid, Biblioteca Nueva, 2006). 
donde transcurrió parte de su adolescencia es, pues, el tema de «La vuelta con Josefina». Hay en la narración un aire nostálgico que todo lo impregna, como «ese ligero olor a humedad de una sala cerrada durante largo tiempo». Sin embargo, la melancolía de aquí no es el dolor punzante que se observa en otras páginas de nuestro autor con análogo asunto; pensemos en «La casa cerrada», el magnífico relato que cierra Castilla (1912), o en «La música» de Lecturas españolas (también de 1912): en estos dos títulos aparece el simbólico tema de la ceguera.

Finalmente, la concepción azoriniana de lo que un artista ha de hacer con el paisaje aparece recogida en un cuento singular: «Mayo» (1.1.1913). Allí, un pintor, que ha cambiado la vida tumultuosa de Madrid por la del campo, madruga cada día para plasmar en el lienzo un momento único, consciente de que «los paisajes no son lo mismo en todas las estaciones. No son lo mismo por la mañana y por la tarde. Dentro de la mañana cambian también de hora en hora, de minuto a minuto». Hay en este pintor, por tanto, algo del narrador que al inicio de La voluntad (capítulo I de la primera parte) nos pinta un amanecer. Casi de la misma forma, el protagonista del relato tiene la certeza de que, cuando haya acabado su obra, habrá aprisionado en ella «una partícula de este mes de mayo esplendente, divino».

\section{Otra serie truncada: los viejecitos}

La simpatía por los viejecitos es una constante en J. Martínez Ruiz. Sin salir del ámbito de estas colaboraciones, su presencia se percibe desde los mismos títulos. Fijémonos en «El viejecito que no sabía nada» (9.6.1904); es un ejemplo de estos «hombres que fueron grandes sabios, y a los cuales ya se les ha olvidado todo». Como otras figuras azorinianas, este personaje vive retirado en una ciudad apacible -tal vez Monóvar- con un acogedor casino. Sus páginas tienen ese aire entre evocador y nostálgico de Las confesiones... y Los pueblos. Siguiendo esa línea evasiva y amable de las colaboraciones en Blanco y Negro, este entrañable viejecito poco tiene que ver con otros grandes hombres que nos conmueven, porque representan un fin de raza, el hundimiento de un mundo, que ellos no pueden remediar; pensemos en la figura del Anciano, trasunto del político Pi y Margall (cap. VI de la segunda parte de La voluntad) o un cuento tan noventayochista, en el fondo, como «El grande hombre en el pueblo» (Los pueblos), que trata sobre los últimos días de Castelar (Lozano, 1990).

Algo distinto nos aportan esos cuentos protagonizados por intelectuales abocados a la senectud, en los que no falta el humor. Dos pertenecen a una serie que se llamaba expresamente «Los viejecitos» («Don Diego de 
Torres», 27.11.1910, y «Luis Cornaro», 11.12.1910); otro -«El criado de Kant» (23.3.1907)-, sin ser de dicha serie, es completamente allegable a los mismos. Este nos narra los últimos días del filósofo Emmanuel Kant, cuando la sustitución de un criado suyo de toda la vida por otro nuevo es capaz de crear un ligero desasosiego en el metódico maestro de Königsberg.

«Don Diego de Torres» es, en cierta manera, una narración de fina ironía. En su primera parte, nos muestra el trabajo intelectual de Torres Villarroel, guiado por su curiosidad universal; pero también nos muestra, en la segunda, cuánto de mistificación hay en su obra. Como es habitual en este tipo de textos, Azorín se fija en un libro de Torres escrito en su juventud, Vida natural y católica, donde el autor salmanticense daba peregrinos consejos para llegar a viejo, tales como llevar una sortija de esmeraldas, zafiros o diamantes (consejos que, naturalmente, él no siguió). A mi ver, el principal acierto del cuento consiste en reivindicar la figura del no siempre valorado escritor dieciochesco ${ }^{14}$.

Más años que Torres Villarroel, sin duda alguna, vivió Luis Cornaro en Italia, desde finales del XV y durante casi todo el siglo XVI. Según nos cuenta Azorín, alcanzó larga vida (en torno a los cien años), simplemente llevando cuidado en el comer y el beber. Escribió sabios consejos para vivir mucho tiempo y llegar a viejo con buena salud, hasta (decía el propio Cornaro) «la aniquilación del húmedo radical, gastado por una extrema vejez». Un cuento más donde -como vemos- campean el humor, la gracia y una fina ironía.

\section{Reelaboraciones de otros textos anteriores}

Miguel Ángel Lozano ya advirtió que muchas páginas de Blanco y Negro son reelaboraciones de otras anteriores (Lozano, 1990). Ilustra lo dicho con «El tío Joaquinito» (8.7.1905), una de esas figuras andaluzas que había aparecido antes en un capítulo de La Andalucía trágica, «Arcos y su filósofo»: se trata de un talabartero, el cual sostiene que para el campesino actual los tres clavos de Cristo son la contribución y el consumo. Ahora bien: lo que en aquel texto es compromiso ante las injusticias que sufre el campesinado andaluz, se torna suave escepticismo en el «El tío Joaquinito», del que simplemente se nos cuenta su abnegada vida, que aquí es la de ser albardonero, es decir, «sé zastre de bestia»

«Las decadencias» (2.3.1907), a su vez, toma como patrón el capítulo «Sarrió» de Los pueblos. Como en aquel, Azorín, personaje, visita a un viejo

14. Mucho antes de que hispanistas como Guy Mercader se acercasen a su obra o como lo está haciendo ahora, con gran rigor, Manuel M. ${ }^{a}$ Pérez López. 
maestro, para constatar su decrepitud. Pero en este nuevo texto no aparece don Lorenzo Sarrió y, en su lugar, encontramos a un tal don Rafael. Sin localización explícita, se describe la casa de este anciano, toda plagada de símbolos que van anticipando su final: el reloj parado, la sombrilla vieja, el sombrero grasiento y, sobre todo, «un rimero de periódicos con las fajas íntegras, intactos». Luego, don Rafael entabla una conversación con Azorín que, al igual que en el relato de Los pueblos, gira en torno a la vejez, la enfermedad y la decadencia física...

Con el capítulo de Las confesiones... «Es ya tarde» tiene que ver «Las lágrimas del niño» (10.8.1907); pero lo que en el libro de memorias rezuma un tono ensayístico, de confidencia, si se quiere, en la colaboración de Blanco y Negro este es más narrativo. Tomando un alter ego, el niño Juanín, al que volveremos a ver en otra colaboración próxima en el tiempo ( El niño no se acuerda», 24.8.1907), el escritor Martínez Ruiz regresa, otra vez, a su infancia. El narrador cuenta lo que Juanín hace una tarde primaveral al salir de clase, tomada la merienda. Va al campo con sus amigos; se dibuja, pienso yo, una innominada Monóvar, porque «por encima de los tejados pardos asomaban el campanario y la cúpula de la vieja catedral». Llega hasta un riachuelo ${ }^{15}$. Y «cuando Juanín ha vuelto a su casa era ya muy tarde». Ha ocurrido, pues, un encontronazo con su padre (que «no ha podido contenerse») y «ha sentido por primera vez el desprecio, el rencor y la ira; una amargura infinita -una amargura infinita que ya acaso a lo largo de su vida no le abandone- ha entrado en su cerebro virgen, limpio, inocente» ${ }^{16}$.

\section{Bliografía}

Auladell, Miguel Ángel (2009), «Azorín, retratista de poetas»; Pascale Peyraga (coord.), Los retratos de Azorín, Alicante, Instituto de Cultura Juan Gil-Albert, pp. 243-264.

EsteVe López, Ana María (1995), «La pintura como fuente de inspiración en Azorín (La ventana del arte)»; Actes du IIIe Colloque International «Azorín (1904-1924)». Pau, Biarritz, 1995, Murcia, Universidades de Pau y Murcia, pp. 41-51.

15. A las afueras de Monóvar, había «un ramblizo, con su hilito de agua» (Memorias inmemoriales, cap. XXXIII, «Lugares»). Azorín, en Agenda, 1959, nos habla no de un riachuelo, pero sí de una rambla -apenas un hilo de agua-, a la que llaman «el Tarrafa», en el capítulo del mismo nombre.

16. Azorín, en Memorias inmemoriales, recuerda: «Como su padre tuviera a veces arranques de impetuosa violencia, él quedaba postrado cada vez que, sin poder sofrenarse, tenía los mismos ímpetus» (cap. XIV, «La herencia»). 
FOX, E. Inman (1992), Azorín: Guía de la obra completa, Madrid, Castalia. García Mercadal, José, ed. (1963), Azorín, En lontananza, Madrid, Bullón.

LozAnO MARCO, Miguel Ángel (1990), «Las colaboraciones de Azorín en Blanco y Negro. El camino hacia España. Hombres y paisajes (1909)»; España Contemporánea, III, núm. 1, pp. 25-46.

- (1993), «Cuatro capítulos de Lecturas españolas», Ínsula, 556, pp. 9-10.

MARTín, Francisco J. (2002), «El Político frente al 'problema de España», Estudios sobre «El Político» de Azorín, Valencia, Biblioteca Valenciana, pp. 67-81.

- (2007), «Introducción» a su ed. de El Político de Azorín, Madrid, Biblioteca Nueva, pp. 11-123.

MARTínEz CACHERO, José María (1985), «Una especie literaria ambigua: los cuentos crítica de Azorín»; Actes du premier Colloque International José Martínez Ruiz, Azorín. Pau, 1985, Biarritz, J\&D Éditions, pp. 189-195.

MARTínez Del Portal, María (1998), «Introducción. Los cuentos de J. Martínez Ruiz»; Azorín, Obras escogidas, III, Madrid, Espasa Calpe, pp. 405-441.

- (1998), «Sobre unas cartas a la educanda Luisa Ruiz y Maestre», M. ${ }^{a}$ Carmen Rico Navarro (coord.), Azorín y Petrer, Ajuntament de Petrer, Caixa de Crèdit de Petrer, Universitat d'Alacant, pp. 85-89.

- (2005), «Introducción» a su ed. Azorín, Las confesiones de un pequeño filósofo, Madrid, Biblioteca Nueva, pp. 13-45.

PavíA, Salvador (1998), «Azorín y Petrel»; M. ${ }^{a}$ Carmen Rico Navarro (coord.), Azorín y Petrer, Ajuntament de Petrer, Caixa de Crèdit de Petrer, Universitat d'Alacant, pp. 11-48.

PayÁ Bernabé, José (1998), «Algunos datos de la vinculación de Azorín con

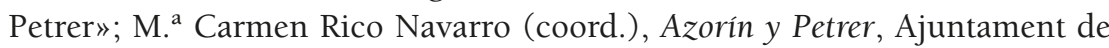
Petrer, Caixa de Crèdit de Petrer, Universitat d'Alacant, pp.101-116.

- (2001), «Azorín, Monóvar y Superrealismo», Actes du V Colloque International «Azorín et le Surréalisme», Gardonne, Éditions Fédérop, pp. 17-32.

PRIETO DE PAUlA, Ángel L. (2006), «El pueblo como construcción imaginaria en Azorín»; Azorín frente a Nietzsche y otros asedios noventayochistas, Alicante, Aguaclara, pp. 167-194.

Riopérez MilÁ, Santiago (1979), Azorín íntegro, Madrid, Biblioteca Nueva.

VAlverde, José María (1971), Azorín, Barcelona, Planeta; en Obras completas, 2 , Madrid, Trotta, 1998.

Vidal Ortuño, José Manuel (2007), Los cuentos de José Martínez Ruiz (Azorín), Murcia, Universidad de Murcia.

- (2010), «Introducción» a Azorín, España, Madrid, Biblioteca Nueva, pp. 9-56.

Fecha de recepción: 01/04/2014

Fecha de aceptación: 15/09/2014

Anales, 26, 2014, pp. 521-535 